\title{
Influence of the Meridional Shifts of the Kuroshio and the Oyashio Extensions on the Atmospheric Circulation
}

\author{
Claude Frankignoul and Nathalie Sennéchael \\ LOCEAN/IPSL, Université Pierre et Marie Curie, Paris, France \\ YOUNG-OH KWON \\ Woods Hole Oceanographic Institution, Woods Hole, Massachusetts \\ Michael A. AlexAnder \\ NOAA/ESRL, Boulder, Colorado
}

(Manuscript received 16 March 2010, in final form 18 August 2010)

\begin{abstract}
The meridional shifts of the Oyashio Extension (OE) and of the Kuroshio Extension (KE), as derived from high-resolution monthly sea surface temperature (SST) anomalies in 1982-2008 and historical temperature profiles in 1979-2007, respectively, are shown based on lagged regression analysis to significantly influence the large-scale atmospheric circulation. The signals are independent from the ENSO teleconnections, which were removed by seasonally varying, asymmetric regression onto the first three principal components of the tropical Pacific SST anomalies. The response to the meridional shifts of the OE front is equivalent barotropic and broadly resembles the North Pacific Oscillation/western Pacific pattern in a positive phase for a northward frontal displacement. The response may reach $35 \mathrm{~m}$ at $250 \mathrm{hPa}$ for a typical OE shift, a strong sensitivity since the associated SST anomaly is $0.5 \mathrm{~K}$. However, the amplitude, but not the pattern or statistical significance, strongly depends on the lag and an assumed 2-month atmospheric response time. The response is stronger during fall and winter and when the front is displaced southward. The response to the northward KE shifts primarily consists of a high centered in the northwestern North Pacific and hemispheric teleconnections. The response is also equivalent barotropic, except near Kamchatka, where it tilts slightly westward with height. The typical amplitude is half as large as that associated with OE shifts.
\end{abstract}

\section{Introduction}

Observational evidence that extratropical sea surface temperature (SST) anomalies have an influence on the large-scale atmospheric circulation during certain seasons has been found in the North Atlantic (Czaja and Frankignoul 1999, 2002; Rodwell and Folland 2002) and the North Pacific (Liu et al. 2006; Frankignoul and Sennéchael 2007, hereafter FS07). These air-sea interactions are highly relevant to the short-term climate predictability, as the SST anomalies tend to be rather persistent because of SST anomaly reemergence, sustained forcing from the tropics, and low-frequency changes

Corresponding author address: Claude Frankignoul, LOCEAN/ IPSL, Université Pierre et Marie Curie, 4 Place Jussieu, 75252 Paris CEDEX 05, France.

E-mail: cf@locean-ipsl.upmc.fr in oceanic heat advection. The extratropical SST variability is large near the strong SST gradients along the oceanic fronts associated with western boundary currents and their extensions (hereafter WBCs), especially at decadal time scales (Nakamura et al. 1997; Nakamura and Kazmin 2003; Kwon et al. 2010a), when the changes in the oceanic circulation are particularly effective at affecting SST (Qiu 2002; Vivier et al. 2002; Schneider et al. 2002). Major storm tracks are organized along or just downstream of the main oceanic frontal zones. Nakamura et al. (2004) argued that differential heat supply across a midlatitude frontal zone acts to maintain surface baroclinicity, sustaining storm development and the anchoring effect of the SST frontal zones, as found for the Kuroshio and Oyashio Extension (KOE) region during spring (Taguchi et al. 2009). Similarly, the large heat release from the Gulf Stream forces a basin-scale tropospheric response (Minobe et al. 2008). However, the large-scale 
impact of anomalous frontal displacement remains to be established.

As reviewed by Small et al. (2008), there is ample evidence that the atmospheric boundary layer is locally affected by the SST variability near oceanic fronts, and Joyce et al. (2009) found that the large-scale shifts in the Gulf Stream and the Kuroshio Extension (KE) path were causing significant changes in the year-to-year nearsurface synoptic activity. Observational attempts to relate large-scale tropospheric fluctuations in the North Atlantic sector to prior changes of the Gulf Stream have failed (Frankignoul et al. 2001), but the atmospheric circulation in the North Pacific sector appears to be influenced by SST anomalies in the KE region (FS07; Qiu et al. 2007). However, lacking a reliable indicator of the $\mathrm{KE}$ jet changes, the signals could not be firmly linked to the oceanic circulation. More direct evidence of WBC influence was provided by Hirose et al. (2009), who showed that changes in the Tsushima Warm Current (a current fed by the Kuroshio, which passes between Korea and Japan) during autumn were correlated with the western Pacific (WP) pattern and its surface counterpart, the North Pacific Oscillation (NPO), the second dominant mode of wintertime sea level pressure (SLP) variability in the North Pacific (Wallace and Gutzler 1981; Linkin and Nigam 2008), during the following winter.

There are two frontal zones in the western North $\mathrm{Pa}$ cific: the front associated with the $\mathrm{KE}$ and the subarctic front associated with the Oyashio Extension (OE). The $\mathrm{KE}$ front is deep but has a modest SST gradient, while the $\mathrm{OE}$ is shallow and has a strong SST gradient, and their decadal variability is not necessarily coherent (Nonaka et al. 2006). Previous studies have shown that the KE responds to basin-scale wind forcing with a delay of 2-4 yr linked to baroclinic Rossby wave propagation (e.g., Seager et al. 2001; Schneider et al. 2002; Qiu 2003). Using satellite altimetry data, Qiu and Chen (2005) found that the KE path tends to migrate northward when the $\mathrm{KE}$ jet strengthens, and vice versa. On the other hand, Taguchi et al. (2007) and Ceballos et al. (2009) suggested, based on an eddy-resolving oceanic hindcast, that the $\mathrm{KE}$ variability separates into two EOFs: one describing the KE meridional shifts and linked to the Aleutian low, and the other changes in the KE strength mainly forced by the NPO. However, the two modes are not well separated in the satellite altimetry era or in the period considered here, and EOFs artificially separate a shift and intensification into two independent modes (Qiu and Chen 2010). The transport of the Oyashio rapidly responds to the wind stress changes associated with the Aleutian low via barotropic Rossby wave propagation (e.g., Isoguchi et al. 1997) and to local Ekman pumping via baroclinic wave propagation. It is also remotely forced about three years before by wind stress curl anomalies in the central Pacific (Qiu 2002; Nonaka et al. 2008).

If $\mathrm{WBC}$ influence on the atmospheric circulation reinforces or damps the atmospheric modes that mainly force the WBC changes (two-way coupling), it could enhance the decadal climate variability. Several climate model simulations suggest that this occurs in the North Pacific (e.g., Latif and Barnett 1994; Pierce et al. 2001; Kwon and Deser 2007), but the atmospheric response differs among the modeling studies, and the horizontal resolution was insufficient to resolve the dual fronts in the western North Pacific.

In this paper, we use observational estimates to investigate whether the meridional shifts of the $\mathrm{KE}$ and the OE have a significant influence on the large-scale atmospheric circulation. Section 2 describes the observational data. Section 3 describes how WBC indices are constructed and discusses their relation to SST and previous atmospheric forcing. Section 4 gives the methodology used to determine the WBC influence on the atmosphere, which is based on the assumption that the extratropical atmospheric time scale is much smaller than that of the WBC (Frankignoul et al. 1998). As this does not hold in the North Pacific, which is strongly influenced by El Niño-Southern Oscillation (ENSO) teleconnections, substantial effort is devoted to removing the ENSO signal (refer to the appendix). The atmospheric response to the WBC shifts is investigated in section 5 and discussed in section 6 .

\section{Data}

Monthly anomalies of SLP, geopotential height at 250 and $500 \mathrm{hPa}$ (Z250 and Z500, respectively), surface wind stress, and SST were taken from the National Centers for Environmental Prediction-National Center for Atmospheric Research (NCEP-NCAR) reanalysis (Kistler et al. 2001) for the period 1980-2008. We also considered version 2 of the National Oceanic and Atmospheric Administration optimal interpolation $1 / 4^{\circ}$ daily SST (AVHRR-only product) (NOAA OISST; Reynolds et al. 2007) for 1982-2008. The North Pacific SST climatology and the standard deviation of the monthly SST anomalies are shown in Fig. 1a. The SST variability is largest in the $\mathrm{KOE}$ region, peaking near the $\mathrm{OE}$ front. However, the NCEP-NCAR reanalysis uses coarseresolution SST, so that the atmospheric circulation does not respond to small-scale SST variations. Yet, it is expected that the atmospheric observations assimilated in the model nudge the large-scale response to the SSTs to the one driven by the small shifts in the KOE fronts. The bottom panel in Fig. 1 shows the time evolution of the SST anomaly in a box centered on the $\mathrm{KE}\left(30^{\circ}-40^{\circ} \mathrm{N}\right.$, 

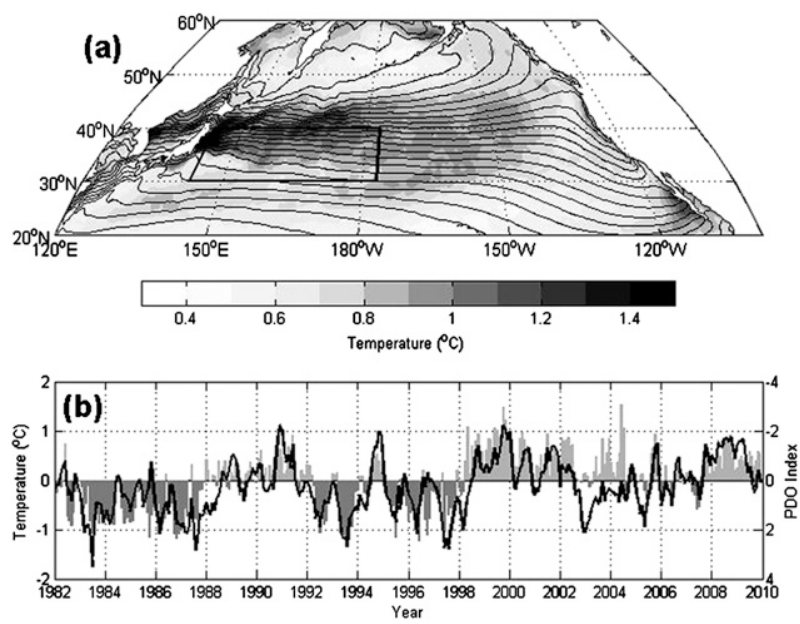

FIG. 1. (a) Mean SST (contour interval $1^{\circ} \mathrm{C}$ ) and standard deviation of monthly SST anomalies for 1982-2008, based on the NOAA OI $1 / 4^{\circ}$ data. The black line defines the KE box. (b) Time series of the averaged SST anomalies in the KE box (shading) and the PDO (black line).

$143^{\circ} \mathrm{E}-183^{\circ} \mathrm{W}$ ) that was shown in FS07 to be representative of the oceanic forcing of the atmosphere in summer, and also corresponds to the largest variability at depth. The time series exhibits an upward trend, large decadal variability, and a high negative correlation $(r=-0.72)$ with the Pacific decadal oscillation (PDO; Mantua et al. 1997) index.

The raw temperature profiles for 1979-2007 from the World Ocean Database 2005 (WOD2005; Johnson et al. 2006; available online at http://www.nodc.noaa.gov/OC5/ WOD05/docwod05.html) and its online update (at http:// www.nodc.noaa.gov/OC5/WOD05/pr_wod05.html) were used to objectively map the 200-m temperature and calculate the KE index.

\section{Variability of the Kuroshio and Oyashio Extensions, and their links to SST}

\section{a. Definition of the $O E$ index}

The OE index (OEI) is defined as the leading principal component (PC) of the latitude of the maximum meridional SST gradient ( $d \mathrm{SST} / d y)$ between $145^{\circ}$ and $170^{\circ} \mathrm{E}$. Longitudes west of $145^{\circ} \mathrm{E}$ were excluded because the $\mathrm{OE}$ is not clearly distinct from the KE there, and longitudes east of $170^{\circ} \mathrm{E}$ were not considered because the $\mathrm{OE}$ front becomes too diffuse. First, $d \mathrm{SST} / d y$ was calculated from the monthly-mean NOAA OISST with $0.25^{\circ}$ resolution for 1982-2008. Then, the latitude of OE at each longitude and month was taken as the latitude of maximum $d \mathrm{SST} / d y$ between $35^{\circ}$ and $47^{\circ} \mathrm{N}$ (Fig. 2). After removing a linear trend and the mean seasonal cycle at

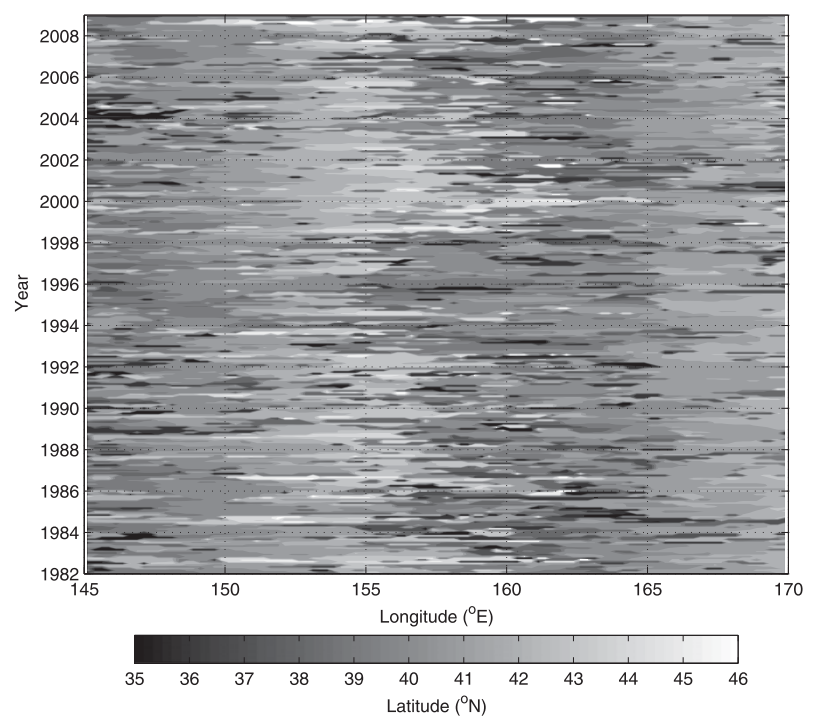

FIG. 2. Hovmöller diagram of the latitude of maximum meridional SST gradient.

each longitude, EOFs were calculated for the monthly OE latitude. The leading EOF represents a large and coherent north-south shift, explaining $13 \%$ of the total variance (Fig. 3a). A similar EOF pattern, but with $32 \%$ of the total variance explained, is obtained when a moving average with a 13-month triangular weight is applied before the EOF calculation. However, the unsmoothed OE index (Fig. 3c) will be used since it provides higher temporal resolution, which is more appropriate to detect an atmospheric response that involves a response time of a couple of months.

After removal of a third-order trend, the regression of SLP on the OEI when SLP leads by 0-24 months yields atmospheric forcing patterns that resemble the Aleutian low mode, as illustrated for the 1-month lead in Fig. 4. A weaker Aleutian low (positive SLP anomalies) drives a northward shift of the OE, consistent with the modeling study by Nonaka et al. (2008). However, at most lags the SLP anomaly has its center of action between $40^{\circ}$ and $50^{\circ} \mathrm{N}$, which is slightly south of that of the typical Aleutian low mode, and it often has a weaker high over the Bering Sea. The wind stress curl forcing patterns exhibit zonally elongated negative anomalies between $35^{\circ}$ and $50^{\circ} \mathrm{N}$, consistent with the resulting northerly $\mathrm{OE}$ location. At short lag, the maximum wind stress curl is in the central basin, while it extends east of the date line at longer lag (Fig. 4, bottom panels). Nonaka et al. (2008) attributed the fast response to basinwide wind stress curl anomalies and barotropic Rossby wave adjustment, and the slow ( $\sim 3$ years) response to wind stress curl anomalies confined to the west of $170^{\circ} \mathrm{E}$ and baroclinic Rossby wave adjustment. We used a linear baroclinic Rossby 

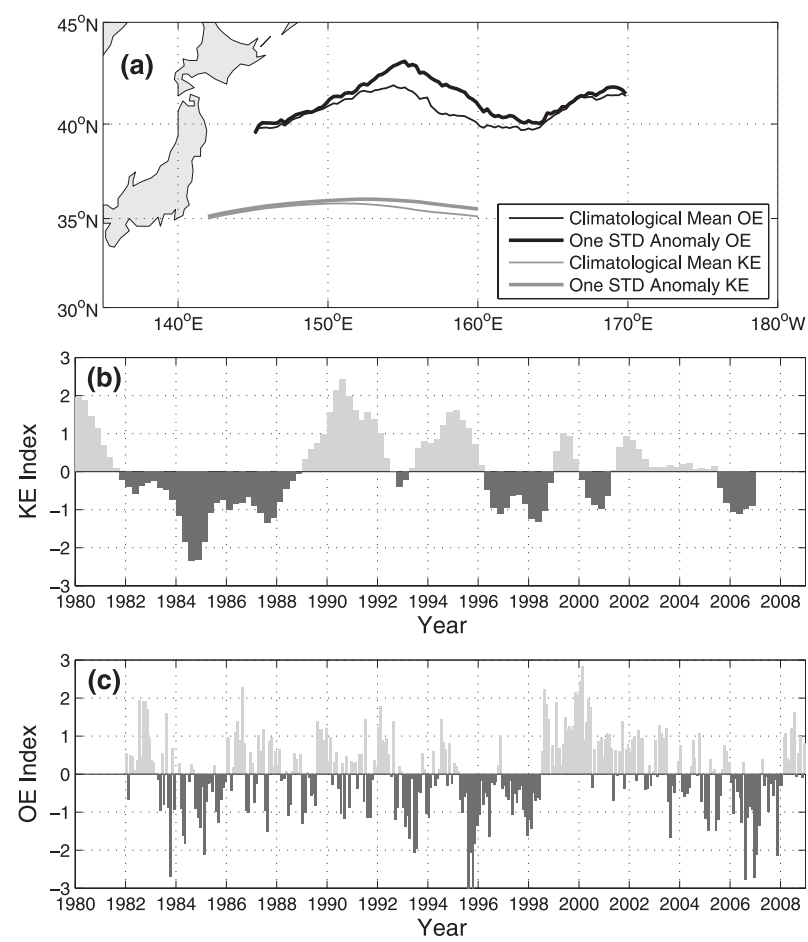

FIG. 3. (a) Mean position of the maximum meridional SST gradient (thin line) and its typical northerly position (thick line), and of the KE (thin gray line) and its typical northerly position (thick gray line) as estimated from the first EOF and a unit value of the corresponding normalized PCs. Time series of the (b) KE and (c) $\mathrm{OE}$ indices.

wave model forced by the monthly wind stress curl anomalies to simulate the slow baroclinic OE response as in Qiu (2003). The correlation between the sea surface height (SSH) hindcast (averaged over $38^{\circ}-45^{\circ} \mathrm{N}, 145^{\circ}-$ $170^{\circ} \mathrm{E}$ ), which reflects the baroclinic OE response, and the OEI, which is dominated by the barotropic OE response, peaks when the OEI leads by $1-2$ yr $(r=0.32$ with monthly resolution and $r=0.59$ with annual resolution). This is consistent with the different adjustment time to wind forcing. Because of the two-time-scale character of the OEI, its autocorrelation drops rapidly at lag $=1$ month $(r=0.4)$ but decreases more slowly at larger lag, with an $e$-folding time of 3-4 months (not shown).

The associated SST pattern based on the smoother NCEP-NCAR product ${ }^{1}$ is shown in Fig. 5 (top). As expected, the SST anomaly is large and positive when the OE front is in a northerly position (positive OEI), but it is much broader than expected from the front displacement alone. It is basinwide, primarily reflecting the Ekman

\footnotetext{
${ }^{1}$ Similar, but more noisy, results are found with the high-resolution SST data.
}
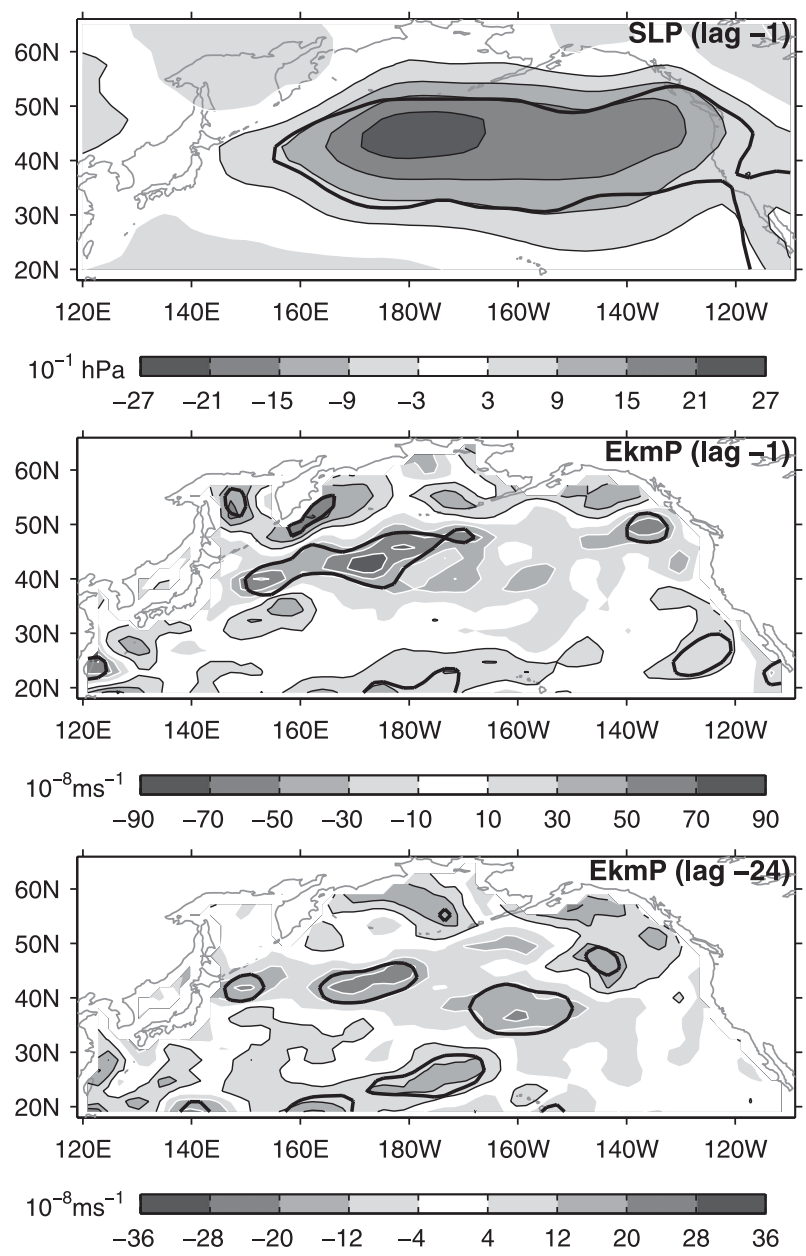

FIG. 4. Regression of SLP (top) and Ekman pumping (middle and bottom) on the OEI when the atmosphere leads by (top and middle) 1 and (bottom) 24 months. White (gray) contours are for negative (positive) values. The black contour indicates 10\% significance.

transport and the surface heat flux associated with the atmospheric fluctuations that displaced the front. Nonaka et al. (2008) also reported a positive correlation between the OE latitude and the SST anomalies in their eddyresolving ocean model simulation. The OEI is significantly correlated with the KE SST index in Fig. 1 and the PDO at lag 0 ( $r=0.39$ and -0.34 with monthly resolution, and $r=0.67$ and -0.60 with yearly resolution, respectively), presumably because they each rapidly respond to Aleutian low forcing. Consistent with Nakamura and Kazmin (2003), the link between the subarctic front and ENSO seems small, with only a weak SST anomaly in the equatorial Pacific.

\section{b. Definition of the $K E$ index}

The KE index (KEI) is based on the first PC of the latitude of the $14^{\circ} \mathrm{C}$ isotherm at $200 \mathrm{~m}$ between $142^{\circ}$ and 

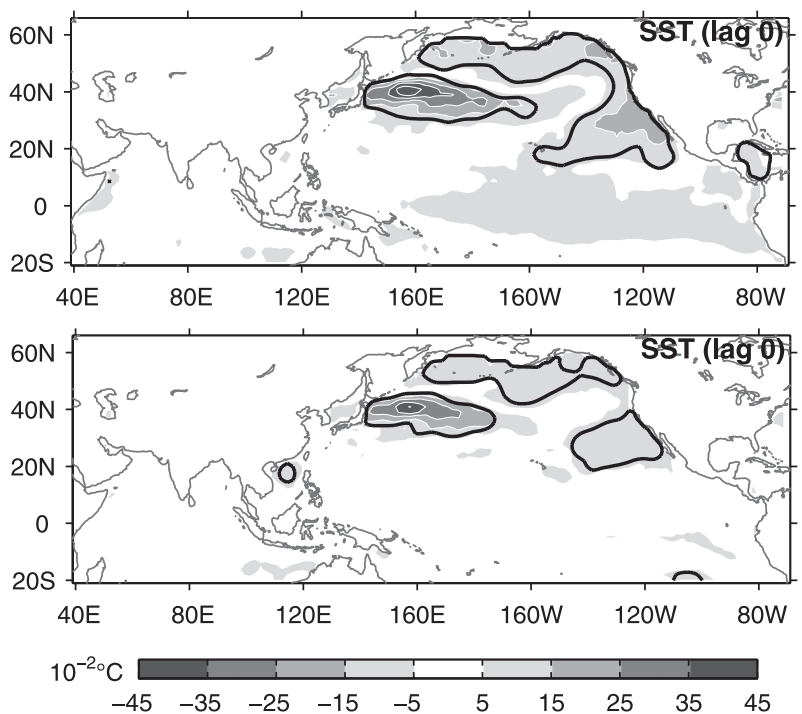

FIG. 5. Regression of the SST anomalies onto the OEI, (top) after removal of a cubic trend and (bottom) after also removing the ENSO signal. White (gray) contours are for negative (positive) values. The black contour indicates $10 \%$ significance.

$160^{\circ} \mathrm{E}$. The $200-\mathrm{m}$ level maximizes data availability while remaining below the winter mixed layer, but it is above the strongest subsurface front. The 200-m temperature was objectively mapped for each 3-month period from January-March (JFM) 1979 to October-December (OND) 2007 [e.g., JFM 1980, April-June (AMJ) 1980, etc.] using the raw temperature profiles from the WOD2005 and its online updates. A Poisson-type covariance function with a $500-\mathrm{km}$ decorrelation length scale was used and a mapping error of $10 \%$ was allowed for the objective mapping (Bretherton et al. 1976). In addition, a secondorder polynomial of the form $F(x, y)=a_{0}+a_{1} x+a_{2} y+$ $a_{3} x^{2}+a_{4} y^{2}$ was assumed for the large-scale background field (Le Traon 1990). The latitude of the $14^{\circ} \mathrm{C}$ isotherm was then selected at each longitude and time step. As the data are sparse and noisy because of the strong eddy activity in the KE (Qiu and Chen 2005), a triangular fivepoint moving average was used to remove the variability less than a year, and data points from the first and last years, that is, 1979 and 2007, were discarded. After removing a linear trend at each longitude, an EOF analysis was performed for the latitude of the $14^{\circ} \mathrm{C}$ isotherm with the smoothed seasonal data from JFM 1980 to OND 2006. The leading EOF represents uniform north-south shift of the KE and explains $70 \%$ of the total variance (Fig. 3a). One standard deviation change in the PC corresponds to a meridional shift of about $30 \mathrm{~km}$. The normalized leading PC, after removal of the (small) mean seasonal cycle and a third-order trend, is used as KEI. The KEI is dominated by variability longer than a few
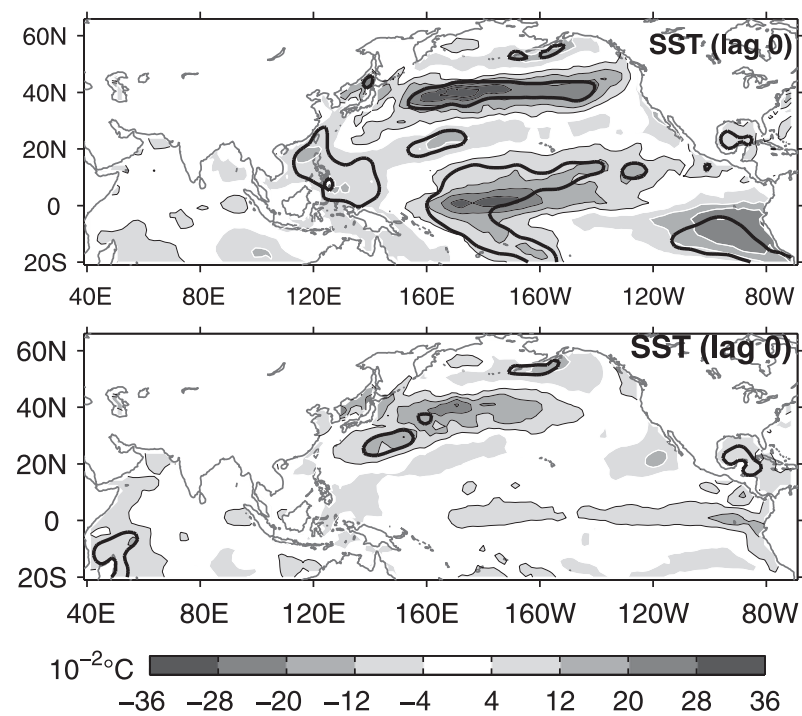

FIG. 6. As in Fig. 5, but for regression of the SST anomalies onto the KE.

years (Fig. 3b), and its autocorrelation function indicates weak oscillations at a $12-14-y r$ period (not shown). A shorter version of the index was used in Joyce et al. (2009).

The SSH derived from satellite altimetry has been used to define a KE index starting in 1993 (e.g., Qiu and Chen 2005). The SSH-based KE index exhibits similar correlations with the SST index; however, it corresponds to larger meridional migrations of the KE path, and it is only moderately correlated $(r=0.52)$ with our $200-\mathrm{m}$ temperature-based KE index. This could be due to spatial smoothing and our use of a relatively shallow level to define the KEI, which may not be fully representative of the position of the subsurface jet.

The origin of the KE fluctuations was examined by regressing the wind stress curl and SLP anomalies onto the KEI (not shown). The SLP regression exhibits a northward shift and weakening of the Aleutian low when SLP leads by $0-2$ yr. The wind stress curl exhibits a band of negative values between $30^{\circ}$ and $45^{\circ} \mathrm{N}$ that almost extends across the whole basin, with a maximum near $165^{\circ} \mathrm{W}$ and maximum correlation when it leads the KEI by $6-8$ seasons. The correlation between the linear Rossby wave model SSH hindcast (averaged over $30^{\circ}-$ $40^{\circ} \mathrm{N}, 142^{\circ}-160^{\circ} \mathrm{E}$ ) and the KEI is 0.60 , which confirms that the KEI primarily reflects a baroclinic response to basin-scale wind stress curl forcing.

The KEI represents the subsurface KE front. The associated SST variability (Fig. 6, top) shows a large signal in the KE region, as well as in the tropical Pacific, where it resembles the second tropical Pacific EOF (see Fig. A1). The simultaneous correlation with the (detrended) KE 
SST index in Fig. 1 is $r=0.39$. However, the maximum correlation occurs when the SST index leads KEI by two seasons $(r=0.49)$. A similar lag is found for the maximum anticorrelation between the PDO and the KEI, possibly because the SST responds faster to the atmospheric forcing than the KE.

\section{c. Relation between the two indices}

The KEI and the (correspondingly smoothed) OEI are practically uncorrelated $(r=0.16)$, even though they covary with the KE SST index and the PDO. Marginally significant correlations are found at lags of 2-3 yr (KEI leads the OEI by $2 \mathrm{yr}$; OEI leads KEI by $3 \mathrm{yr}$ ), but they do not affect the analysis below, which is only based on short time lags.

\section{Estimating the atmospheric response}

In most studies, the response to extratropical SST anomalies was derived from the relation between the atmosphere and prior SST anomalies, since the relation at zero lag or for the atmosphere leading is dominated by the oceanic response to the atmosphere. Frankignoul et al. (1998) assumed that an atmospheric signal $X(t)$ at a given location and time $t$ can be decomposed into a short-time-scale signal that characterizes the intrinsic variability of the atmosphere, say, $n(t)$, and a linear function of an SST anomaly or any other slow variable, such as a WBC index, say, $T(t)$ :

$$
X(t)=F T(t)+n(t),
$$

where $T(t)$ has a much longer time scale than $n(t)$, and $F$ is the response or feedback. Multiplying (1) by $T(t-\tau)$ and taking ensemble average leads to

$$
C_{X T}(\tau)=F C_{T T}(\tau)+C_{n T}(\tau),
$$

where $C_{X T}(\tau)$ denotes the lagged covariance between $X$ and $T$, and a positive $\tau$ indicates that the atmosphere lags the ocean. For $\tau$ much larger than the intrinsic atmospheric persistence, $C_{n T}(\tau)=0$, and $F$ can be estimated by

$$
F=\frac{C_{X T}(\tau)}{C_{T T}(\tau)} .
$$

Recent model studies suggest that the atmospheric response to extratropical SST anomalies takes a few months to fully develop, reflecting the time it takes for the transient eddy-mean flow interactions to transform the initial baroclinic response into a larger equivalent barotropic one (Ferreira and Frankignoul 2005, 2008; Deser et al. 2007). Similarly, the statistical analysis of
Strong et al. (2009) suggests that the maximum impact of persistent sea ice forcing is reached after 2 months. Such a delay would be consistent with the stronger covariance found in the observations when the atmosphere follows the SST anomalies by at least 2 months (Czaja and Frankignoul 2002; FS07). In this case, the relation in (1) should take a more complex form, but it is coarsely approximated here by replacing $T(t)$ by $T(t-d)$, where $d$ is a characteristic delay time. We use $d=2$ months, consistent with Deser et al. (2007). The relation in (3) then becomes for $\tau>d$

$$
F=\frac{C_{X T}(\tau)}{C_{T T}(\tau-d)}
$$

Some caution is required for $\tau=d$ when $F$ is divided by $C_{T T}(0)$. That is, $C_{T T}(0)$ may result from a combination of very fast changes and more persistent variability. However, the atmospheric response to fast changes in boundary forcing tends to be local and baroclinic, and it differs from the longer-term response. Hence, if the WBC in part varies very rapidly as in the OEI case, $F$ should be calculated by only using in (4) the slow contribution to $C_{T T}(0)$, which would be smaller than $C_{T T}(0)$ itself, leading to a larger $F$. This can be easily derived from the autocorrelation function.

In this paper, we consider the atmospheric response to the meridional shifts of the OE and the KE separately, using univariate statistical methods. This is consistent with the negligible correlation between the OEI and the KEI and is also motivated by the different temporal resolution and slightly different time period. However, it should be kept in mind that the estimated atmospheric response may also be influenced by covarying SST (or other) anomalies at different locations.

In the presence of ENSO teleconnections, there is an additional persistent atmospheric component and the decomposition in (1) must be generalized into

$$
X(t)=F T(t-d)+b e(t)+n(t),
$$

where $b$ is a parameter and $e(t)$ is the ENSO time series, assuming a fast atmospheric response to the tropical SST. As shown by Frankignoul and Kestenare (2002) and in the appendix, $F$ can still be estimated provided the ENSO influence is first removed from both $X$ and $T$, and $e(t)$ and $n(t)$ are uncorrelated. However, the latter assumption does not hold on long time scales because of the seasonal footprinting mechanism of Vimont et al. (2003), in which the tropical atmosphere is forced during spring and summer by SST anomalies generated by the NPO during the previous winter. Hence, our assumption that $e(t)$ and $n(t)$ are uncorrelated should be viewed with caution for 
the KE, since the KEI only resolves relatively long time scales for which the subtropical-tropical link may become effective.

Previous observational studies of North Pacific SST influence have attempted to remove the ENSO teleconnections by regression using various degrees of complexity, ranging from linear regression on the concurrent (Qiu et al. 2007) or time lagged (Liu et al. 2006) Niño-3.4 index to seasonally varying regression on two ENSO indices (FS07). In this paper, the ENSO signal is removed by seasonally varying, asymmetric regression onto the first three principal components of the tropical Pacific SST anomalies, which seems quite effective (refer to the appendix). Prior to the analysis, a cubic polynomial was removed from all variables by least squares fit, to reduce the influence of trends and ultra-low frequencies. Similar results were obtained by removing a quadratic trend.

Statistical significance was estimated in two ways, with similar results. First, we tested the correlation between $X(t)$ and $T(t-\tau)$, taking into account the time series persistence (e.g., Bretherton et al. 1999). Statistical significance was then verified nonparametrically, using a block bootstrap approach (randomly permuting the atmospheric time series 500 times in blocks of $2 \mathrm{yr}$ for the OEI and 3 yr for the KEI) (e.g., von Storch and Zwiers 1999). The nonparametric approach is used in all figures. Since the Ekman pumping field is noisy, we use the $10 \%$ significance level; however, similar results are found at the $5 \%$ level.

\section{Response of the atmosphere to $\mathrm{OE}$ and $\mathrm{KE}$ fluctuations}

\section{a. Influence of the $O E$ shifts}

While the correlations between tropical SSTs and the OEI are relatively small after the cubic trend is removed, they are virtually uncorrelated when the ENSO signal is also subtracted out (Fig. 5). A significant and robust influence of the OE variability onto the large-scale atmospheric circulation in the North Pacific sector is detected using (4) when the OEI leads by 2 to about 6 months, with broadly similar patterns. The signal is not significant when the OEI leads by 1 month, presumably because of contamination by the atmospheric forcing of the OE fluctuations and insufficient time for the response to the latter to fully develop.

As illustrated in Fig. 7, the atmospheric response is primarily an equivalent barotropic meridional dipole over the North Pacific, with a large low centered near the date line at $55^{\circ} \mathrm{N}$ and an elongated midlatitude high with two maxima. The pattern is similar to the wintertime NPO/WP patterns (cf. Linkin and Nigam 2008), except
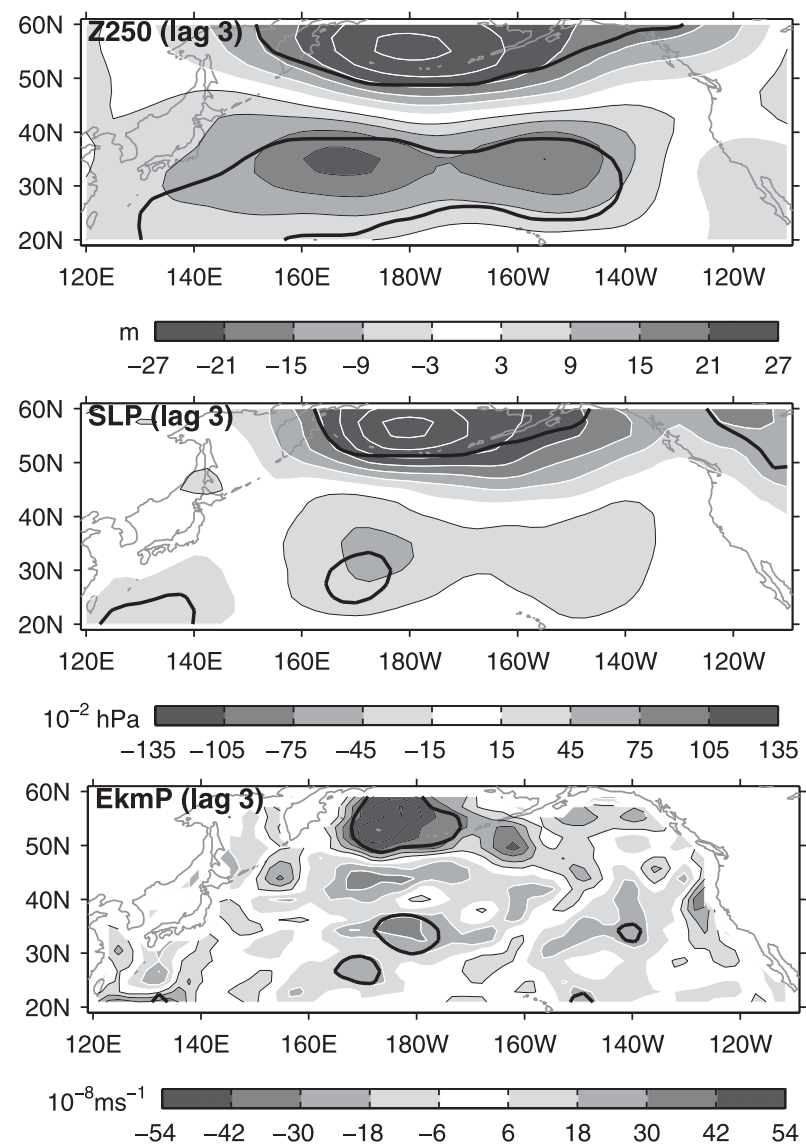

FIG. 7. Estimated response in geopotential height at (top) $250 \mathrm{hPa}$, (middle) SLP, and (bottom) Ekman pumping to a unit value of the OEI (typical northward displacement), assuming $d=$ 2 months, based on lag 3 . White (gray) contours are for negative (positive) values. The dark contours indicate 10\% significance.

for the local high maximum found south and slightly downstream of the OE front. However, the latter is not as strong when the atmospheric response is estimated for the cold season (Fig. 8, top, versus Fig. 10, bottom). The signal is most significant in the middle and upper troposphere (Z250 and Z500, respectively). Based on lag 3 , it reaches about $25 \mathrm{~m}$ for the southern lobe and $35 \mathrm{~m}$ for the northern lobe at $250 \mathrm{hPa}, 25 \%$ less at $500 \mathrm{hPa}$, and 0.8 and $1.7 \mathrm{hPa}$, respectively, for SLP. It is associated with significant hemispheric teleconnections, in particular, significant highs above northeastern America and western Europe, as in the WP pattern (Fig. 8, top). Since the OEI is normalized, this represents the typical magnitude of the signal. However, the amplitude (but not the pattern or the significance) is uncertain, as it depends on the lag and the assumed 2-month response time. Using lag 2 to estimate the amplitude reduces it by a factor of 3 at $250 \mathrm{hPa}$ if (4) is used. However, the amplitude is only reduced by a factor of 2 if only the persistent part of 

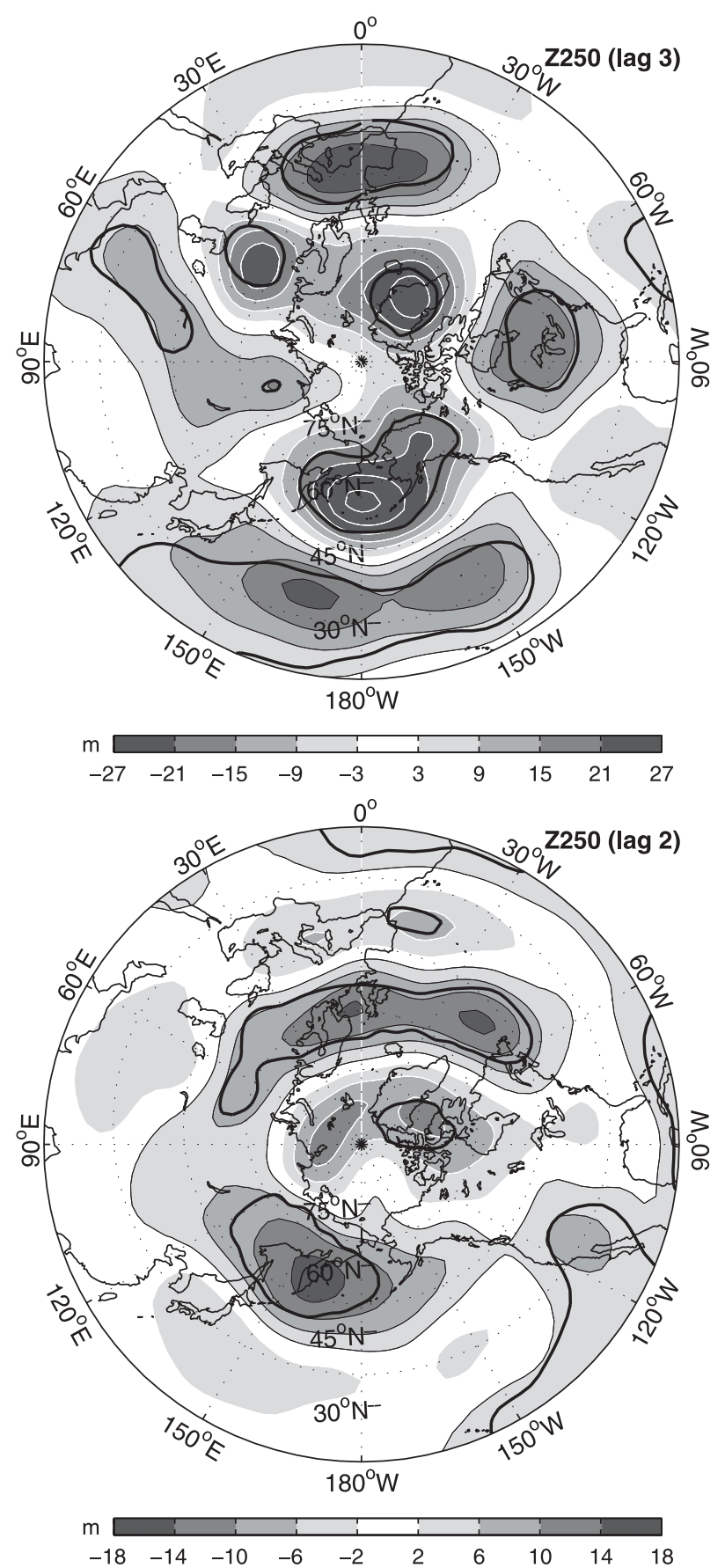

FIG. 8. Hemispheric response at $250 \mathrm{hPa}$ to a unit value of the (top) OEI and (bottom) KEI. White (gray) contours are for negative (positive) values. The dark contours indicate 10\% significance.

$C_{T T}(0)$ is used in the denominator of (4), assuming that the atmosphere has no time to significantly respond to the fast variability ( $\ll 1$ month) of the OEI, as discussed in section 4. On the other hand, using lag 5 (lag 4 is not significant) doubles the amplitude. In addition, assuming an instantaneous response $(d=0)$ would double the amplitude at lag 3, while using a longer delay would decrease it.

The Ekman pumping is noisy and more dependent on the lag, yet suggestive of a significant meridional dipole pattern in the central North Pacific, with Ekman suction along $55^{\circ} \mathrm{N}$ and Ekman pumping between $30^{\circ}$ and $45^{\circ} \mathrm{N}$ (Fig. 7, bottom). Typical fluctuations reach $5 \times$ $10^{-7} \mathrm{~m} \mathrm{~s}^{-1}$. The response to a northward shift of the OE should strengthen the East Kamchatka Peninsula Current. It should also decrease the Oyashio Current strength and shift the OE northward, since the Ekman pumping is negative along the OE. Recall that OE meridional shifts are largely forced by fluctuations in the Aleutian low (section 3a). Although there is little resemblance between forcing and response patterns in the troposphere (cf. Figs. 7 and 4), the Ekman pumping pattern that precedes the OEI shift broadly resembles that which follows it, presumably because the Ekman pumping reflects both the Laplacian of SLP and the atmospheric boundary layer response to the SST front (Feliks et al. 2004; Kelly et al. 2010; Kwon et al. 2010b). Since Ekman pumping plays the leading role in generating the OE shifts, the atmospheric response should act as a weak positive feedback.

A significant asymmetry in the atmospheric response was found when considering separately the northward and southward migration of the OE, although it should be considered with caution in view of the limited sample. As illustrated in Fig. 9, the signal at $250 \mathrm{hPa}$ is slightly stronger and more significant for negative OEI (southward migration). A similar asymmetry is found for SLP, which is only $10 \%$ significant for negative OEI (bottom panel), and for the Ekman pumping (not shown). A dependence on SST polarity is often found in sensitivity studies with atmospheric models (e.g., Kushnir and Lau 1992; Peng et al. 2002), reflecting the importance of the transient eddy - mean flow interactions that largely control the midlatitude atmospheric response to SST forcing.

The seasonal variability of the response was investigated at $250 \mathrm{hPa}$ by only considering sets of three successive months per year. Because of the smaller sample, we did not differentiate between positive and negative OE shifts. The most robust signal appears in fall and winter at lags 2 , 3 , and 5, so that the OEI in summer and fall should have some predictive values for the atmospheric circulation a few months later. As shown in Fig. 10, the winter atmospheric signal in November-January (NDJ), as estimated at lag 3 from the OEI in August-October (ASO), is slightly shifted northeastward relative to when all the calendar months are used, and its similarity with the winter NPO/WP pattern is more striking. The seasonal variability of the response at $250 \mathrm{hPa}$ is illustrated in 

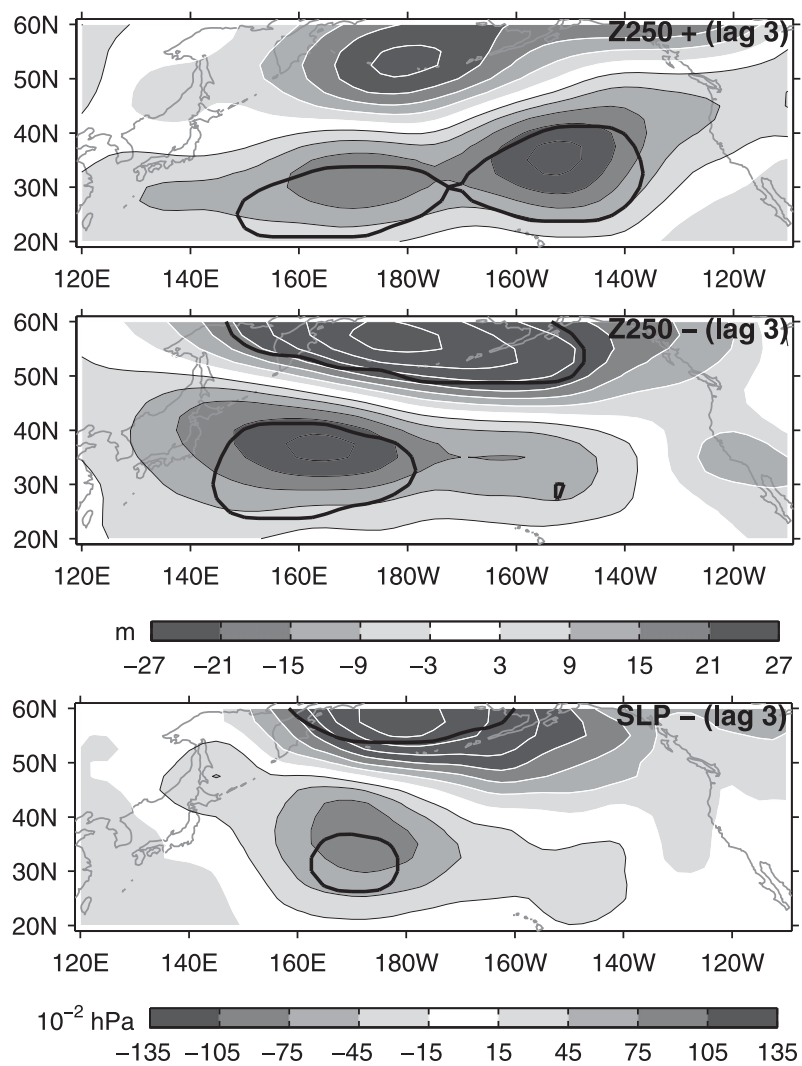

FIG. 9. As in Fig. 7, but for (top) positive and (middle) negative values of the OEI at $250 \mathrm{hPa}$ and (bottom) negative values of OEI at SLP.

Fig. 11 for the Aleutian low region $\left(50^{\circ}-70^{\circ} \mathrm{N}, 160^{\circ} \mathrm{E}-\right.$ $\left.155^{\circ} \mathrm{W}\right)$. The response is mostly significant between October and February, depending on the lag, and it explains up to $10 \%$ of the monthly variance. As before, the estimated response amplitude strongly depends on the lag.

\section{b. Influence of the KE meridional shifts}

Contrary to the OEI, the detrended KEI is substantially modified by ENSO removal and, in particular, its asymmetry, so that the KEI standard deviation decreases by $23 \%$ (Fig. 12). Because of the smoothing, seasonal effects are negligible. The strong influence of the ENSO removal is due to the second ENSO PC, which is highly anticorrelated $(r=-0.54)$ with the KEI, consistent with Fig. 6 (top). Figure 6 (bottom) shows that the tropical SST associated with the KEI was successfully removed by the multivariate regression, except for a small signal in the western Indian Ocean and in the eastern Pacific.

To search for an atmospheric impact of the meridional shifts of the KE jet, we applied the triangular five-point smoothing to the seasonal anomalies of the atmospheric
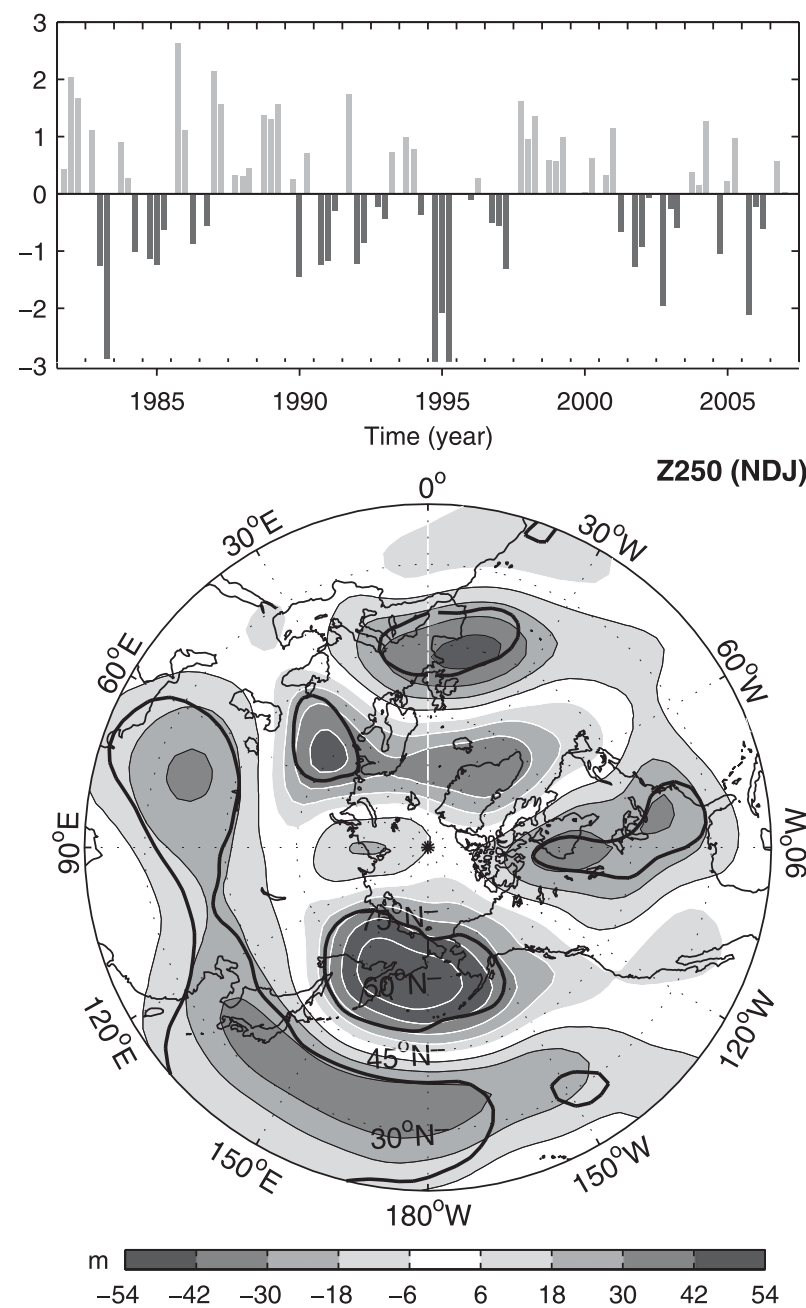

FIG. 10. (top) Time series of the OEI in ASO after cubic detrending and ENSO removal and (bottom) estimated response of the geopotential height at $250 \mathrm{hPa}$ in NDJ to a unit value of the OEI, assuming $d=2$ months. White (gray) contours are for negative (positive) values. The dark line indicates $10 \%$ significance.

fields for consistency. As a result, maps based on (4) are not independent at successive lags. Since lag 0 primarily reflects the oceanic response to the atmospheric forcing, we estimate the atmospheric response from a lag of two seasons (Fig. 13). The signal resembles that at lags 1, 3, and 4 , while drastically differing from the patterns found when the atmosphere leads by one or two seasons. Hence, it appears to indeed represent an atmospheric response.

Figure 13 shows that the response primarily consists of a high in the northwestern North Pacific that tilts westward with height, suggestive of baroclinic structure, and a much weaker low in the KOE region. The pattern shows some similarity with NPO/WP pattern; however, it is shifted westward, the midlatitude lobe is much weaker, and the hemispheric teleconnections (Fig. 8, bottom) are 


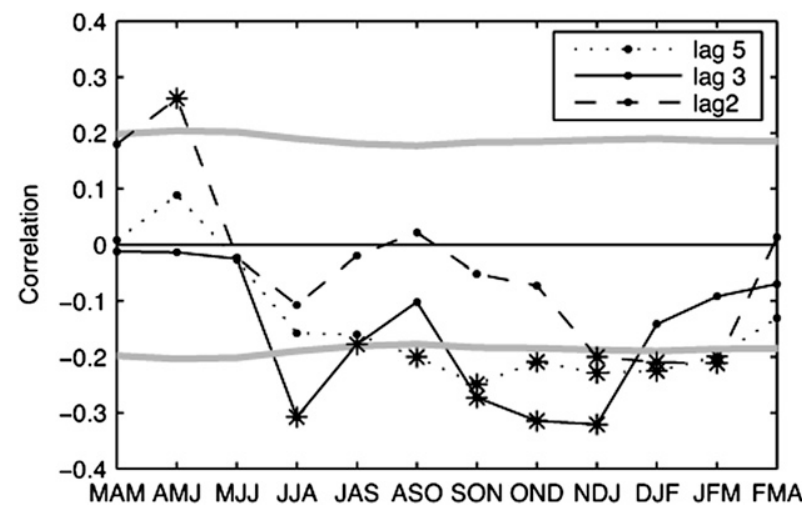

FIG. 11. Seasonal changes in the correlation between the geopotential height at $250 \mathrm{hPa}$ averaged in the box $\left(50^{\circ}-70^{\circ} \mathrm{N}, 160^{\circ} \mathrm{E}-\right.$ $155^{\circ} \mathrm{W}$ ) and OEI leading by 2, 3, and 5 months. The months pertain to the atmospheric response, and the gray line indicates the $10 \%$ significance level.

different. The upper-tropospheric pattern is similar to the 500-hPa winter correlation map shown by Hirose et al. (2009) to follow the changes in the Tsushima Warm Current by one season. In addition, the SLP signal shows a significant high in the subtropical western Pacific that might be indicative of a wave train coming from the tropics. Hence, a contamination by Indian Ocean SST forcing cannot be ruled out (Fig. 6, bottom). The Ekman pumping response to the KE shift (Fig. 13, bottom) shows a banded pattern in the central and western North Pacific with (positive) Ekman suction in the KOE region. Also noteworthy is a broad region of positive Ekman pumping in the southeastern part of the domain.

Since the KEI is based on seasonal means, the amplitude of the response was estimated by using $d=1$, thus assuming an atmospheric response delay of one season rather than 2 months as before. This may lead to a slight underestimation of the response, but it is difficult to quantify because of the strong KEI smoothing. The tropospheric high in Fig. 13 reaches $15 \mathrm{~m}$ at Z250 and $0.6 \mathrm{hPa}$ for SLP, so that the response to the KE shifts is at least twice weaker than in the OE case. This is broadly consistent with the smaller SST signature of the KEI (cf. Figs. 5 and 6), leading to smaller diabatic heating of the atmosphere.

\section{Summary and discussion}

After removing the ENSO teleconnections in a seasonally varying, asymmetric way, the meridional shifts of the OE and the KE were shown to have a significant influence on the large-scale tropospheric circulation. The response patterns and their statistical significance are robust, particularly in the $\mathrm{OE}$ case, but the estimated

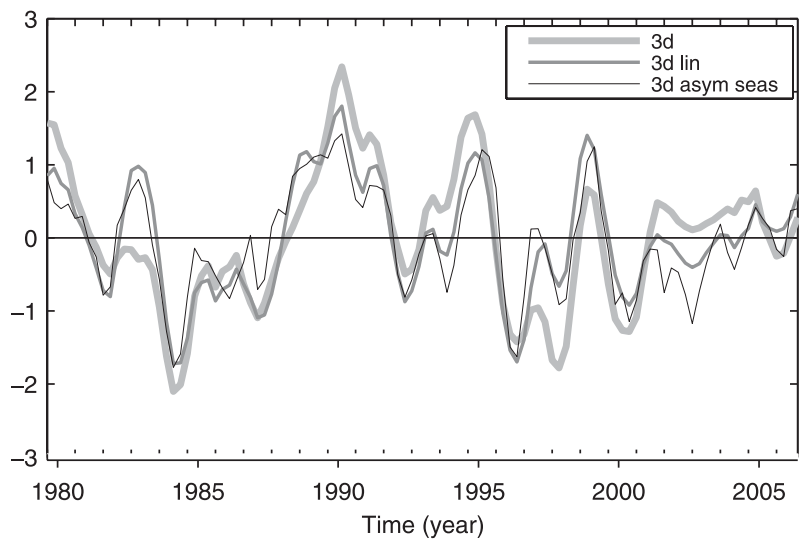

FIG. 12. Time series of the normalized KEI after cubic detrending (thick gray line) and after also removing the ENSO signal linearly (gray line) or asymmetrically with seasonal dependence (thin black line). It is the latter curve that is used, after normalization, in the analysis to obtain the atmospheric response.

amplitudes are quite sensitive to the lag and the assumed 2-month delay in the atmospheric response.

A strong equivalent barotropic atmospheric signal lags the meridional shifts of the OE front. The response resembles an NPO/WP pattern in a positive phase for a northward shift and in a negative phase for a southward shift, with significant teleconnections over northeastern North America and western Europe. It is more significant when the front is displaced southward, although some caution is advised on the significance of the nonlinearity, given how short the data records are. When the data are seasonally stratified, the signal can be mostly detected in fall and winter (ONDJF), and it is even more NPO/WPlike. Linkin and Nigam (2008) have shown that a positive NPO phase is associated with a meridionally tighter and eastward-extended storm track. Hence, the response to the meridional shifts of the OE front may be linked to the anchoring effect of oceanic frontal zones on storm development (Nakamura et al. 2004). The wind stress curl pattern that primarily forces the meridional OE shifts and that which responds to them shows some similarity, suggesting that a weak positive feedback may reinforce the variability of the North Pacific subpolar gyre.

Based on lag 3, the response to typical OE shifts is large, typically reaching about $35 \mathrm{~m}$ at $250 \mathrm{hPa}$ and $25 \%$ less at $500 \mathrm{hPa}$. As the SST anomaly associated with the OE shifts is about $0.5 \mathrm{~K}$, such atmospheric sensitivity would be larger than that suggested by AGCM response studies (e.g., Kushnir et al. 2002; Peng et al. 2003), which ranges between 20 and $40 \mathrm{mK}^{-1}$ at $500 \mathrm{hPa}$. However, none of the AGCMs had enough spatial resolution to represent the sharp SST front associated with the OE, which is crucial to favor the storm-track development. In addition, smaller (larger) amplitudes are obtained at 

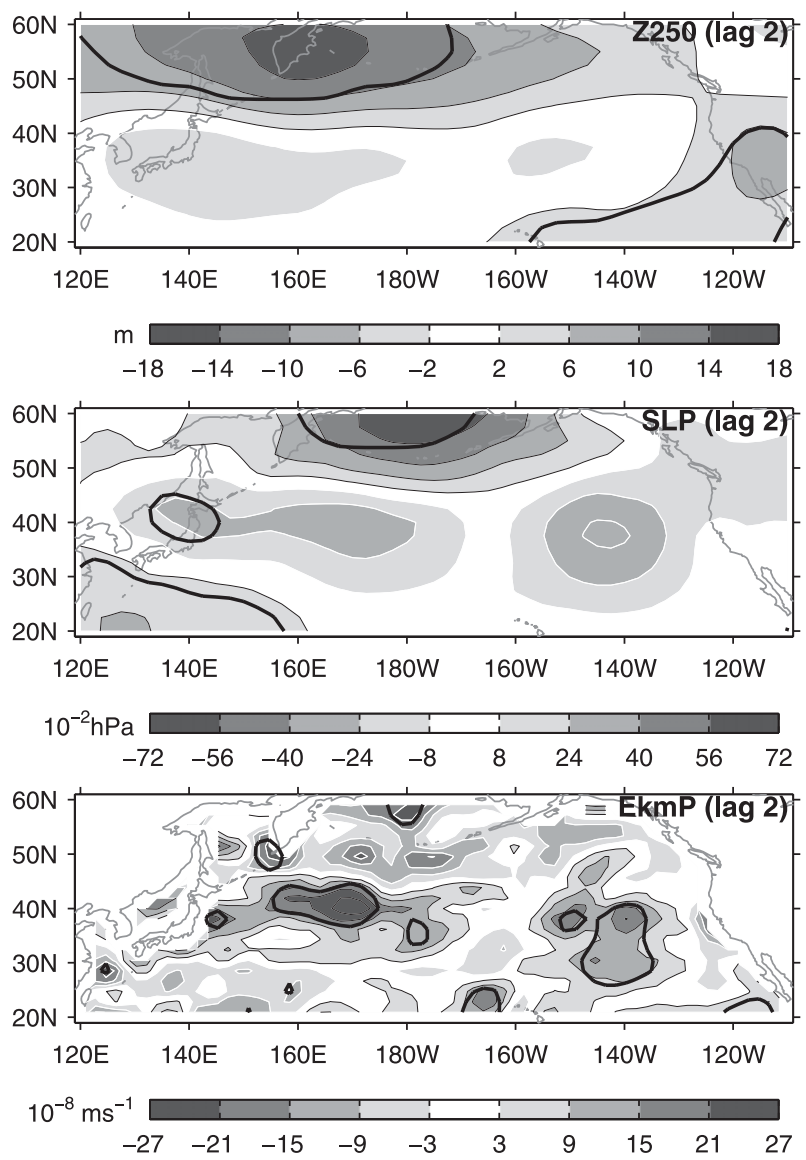

FIG. 13. Estimated response to a unit value of the KEI, based on a lag of 2 seasons, assuming $d=1$ season. White (gray) contours are for negative (positive) values. The thick continuous line indicates the $10 \%$ significance level.

smaller (larger) lag, so that the estimated sensitivity (but not the response pattern or its significance) is uncertain. In any case, up to $10 \%$ of the monthly variance in the Aleutian low region may be predictable in fall and winter from the OEI a few months in advance.

A significant tropospheric response was also found for the KE shifts, which were derived with less spatial and temporal resolution (due to data limitation) from the temperature at 200-m depth along the KE mean axis. The response to a northward shift is an equivalent barotropic high centered in the northwestern North Pacific, with a much weaker low in the KOE region, and significant hemispheric extensions, with a low over northern Europe. The Ekman pumping response to a northward $\mathrm{KE}$ shift is positive in the KOE region and the southeastern North Pacific, possibly acting as a (delayed) negative feedback as in Qiu et al. (2007). The typical response amplitude is smaller than for the OE shifts, reaching about $15 \mathrm{~m}$ at $250 \mathrm{hPa}$; however, the SST associated with the KE shift is also smaller.
The influence on the atmosphere of the meridional shifts of the OE is very different from that of the KE, nearly opposite at high latitude but for a zonal shift, even though both are associated for northward shifts with a SST warming in the KOE region. Although the warming associated with KE differs from and extends farther eastward than that associated with the OE, we speculate that the different responses are primarily related to different physics, namely the anchoring effect of the storm track along the sharp OE front versus the broad latent heat release associated with the KE variability.

A summer tropospheric signal was found by FS07 to be significantly linked to previous basinwide SST anomalies with maximum amplitude in the KE region (see also Kwon et al.2010a), and they speculated that it was related to the variability of the KE. Our KEI is too smoothed to investigate seasonal influence, but the response to the $\mathrm{KE}$ shifts is very different. In addition, little influence of the OE shifts could be detected in summer. Hence, the summer signal in FS07 is unlikely to be driven by meridional WBC shifts, presumably because the SST fronts are weaker and radiative processes more influential during summer.

A number of issues require further investigation. The atmospheric fields were taken from the NCEP-NCAR reanalysis, which uses the coarse-resolution SST. Thus, the atmosphere could not respond to sharp SST fronts. Although it is hoped that the atmospheric observations assimilated in the model could nudge the large-scale response to the one driven by the small frontal shifts considered here, a higher-resolution reanalysis should be used. Our KEI is only moderately correlated with the $\mathrm{KE}$ index derived from satellite altimeter data, and the meridional shifts are smaller. This difference may be linked to spatial smoothing and our use of a relatively shallow level to define the KE, but it needs to be understood. Our analysis is based on univariate regression, consistent with the OEI and the KEI being virtually uncorrelated; however, their influence on the atmosphere, which should primarily arise from local changes in SST and surface heat exchanges, cannot not be distinguished from that of the basin-scale SST anomalies that covary with the WBC shifts. We have assumed that the atmospheric ENSO teleconnections are in phase with the ENSO forcing, even though they take approximately 2-6 weeks to be established (Liu and Alexander 2007). Although our use of three ENSO PCs includes some lags (e.g., PC 2 tends to lead PC 1 by $\sim 8$ months) and the PCs are rather persistent, this is not strictly valid, nor is our assumption that the ENSO indices are uncorrelated with the intrinsic midlatitude atmospheric variability in the KE case. Also, the KEI after ENSO removal is still associated with a small tropical SST signal in the Indian 
Ocean and in the eastern equatorial Pacific, so that it cannot be excluded that the estimated response to the KE shifts is slightly contaminated. Finally, the amplitude of the estimated responses strongly depends on the lag and the assumed delay in the atmospheric response. This reflects the oversimplification of our representation of the transient atmospheric response to frontal shifts, which should be investigated with atmospheric models with sufficiently high resolution and more realistically represented in the analysis.

Acknowledgments. The NCEP-NCAR reanalysis data were provided through the NOAA/OAR/ESRL PSD in Boulder, Colorado, from its Web site (available at http:// www.esrl.noaa.gov/psd/). Discussion with B. Qiu and N. Schneider and the thoughtful comments of B. Taguchi and an anonymous reviewer are acknowledged. This work was supported in part by the L'Institut universitaire de France (CF), the WHOI Heyman fellowship, and the NASA Grant with Award NNX09AF35G (Y.-O. K), and grants through NOAA's Climate Variability and Predictability Program (MAA).

\section{APPENDIX}

\section{Removing ENSO}

To estimate $F$ from (5), let us define

$$
\begin{aligned}
& \hat{X}(t)=X(t)-\frac{C_{X e}}{C_{e e}} e(t) \text { and } \\
& \hat{T}(t)=T(t)-\frac{C_{T e}(d)}{C_{e e}} e(t+d),
\end{aligned}
$$

where the lag of the covariance is omitted when it is zero. Replacing $X$ by (5) and using (A2) yields

$$
\hat{X}(t)=F \hat{T}(t-d)+\frac{F C_{T e}(d)+b C_{e e}-C_{X e}}{C_{e e}} e(t)+n(t) .
$$

Since $n$ and $e$ are uncorrelated $\left(C_{n e}=0\right)$, one has from (5)

$$
C_{X e}=F C_{T e}(d)+b C_{e e} .
$$

Replacing in (A4) yields

$$
\hat{X}(t)=F \hat{T}(t-d)+n(t) .
$$

Now $F$ can be estimated by (4). The generalization to several ENSO time series is straightforward.
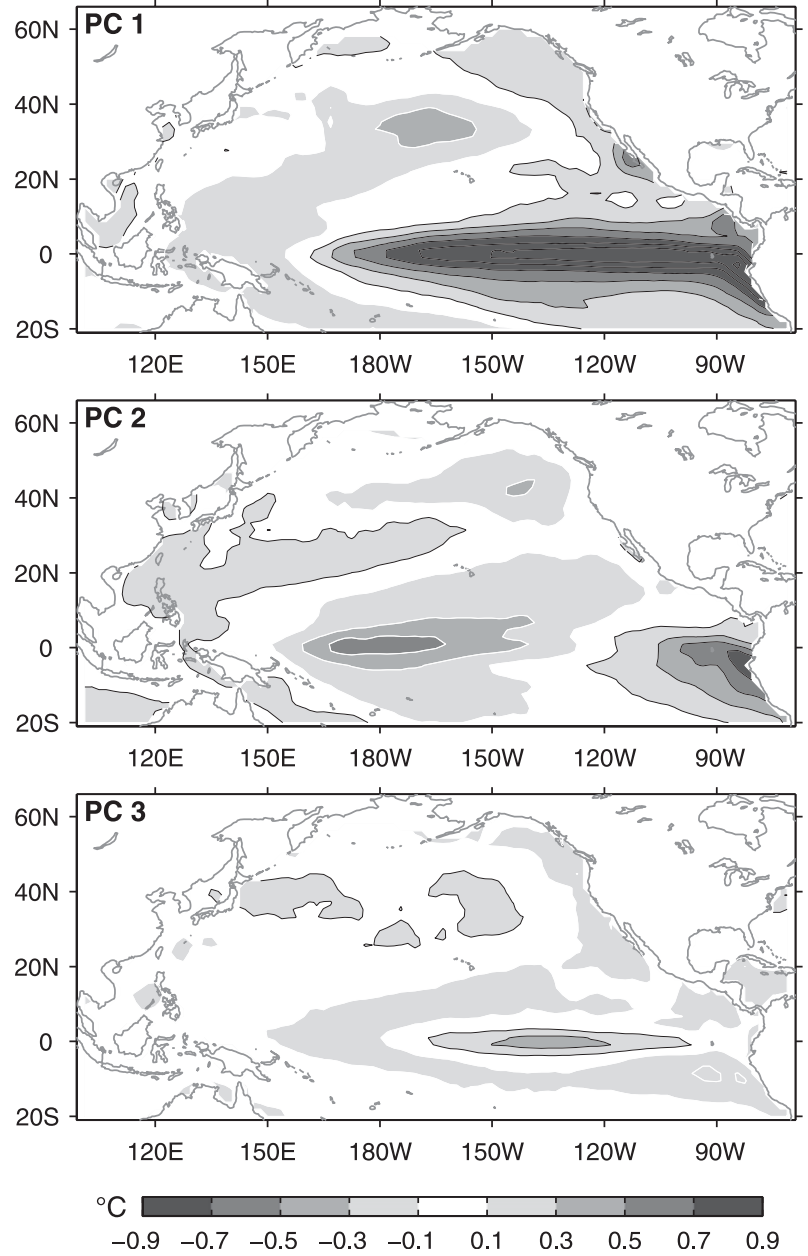

FIG. A1. Regression of the monthly SST anomalies (K) onto the (top) first, (middle) second, and (bottom) third normalized PC of the (detrended) tropical Pacific SST anomalies. White (gray) contours are for negative (positive) values.

In this paper, the ENSO signal is given by the first three PCs of monthly SST anomalies in the tropical Pacific between $12.5^{\circ} \mathrm{N}$ and $12.5^{\circ} \mathrm{S}$. The first mode $(61 \%$ of the variance) roughly corresponds to Niño-3.4. The second (14\% of the variance) represents the east-west SST contrast. The third mode ( $4 \%$ of the variance) has a narrow maximum along the equator. The associated SST anomalies (Fig. A1) are substantial in the North Pacific. Two PCs or indices are generally used to represent the different types of ENSO (e.g., Trenberth and Stepaniak 2001; Kao and Yu 2009) and the SST asymmetry between El Niño and La Niña (Hoerling et al. 1997; Straus and Shukla 2002). The third mode was included as it plays a role at the end of the ENSO events (see Fig. A3). Similar results were obtained when only using the first two PCs, but the response to the OE fluctuations was slightly smaller and less significant. 

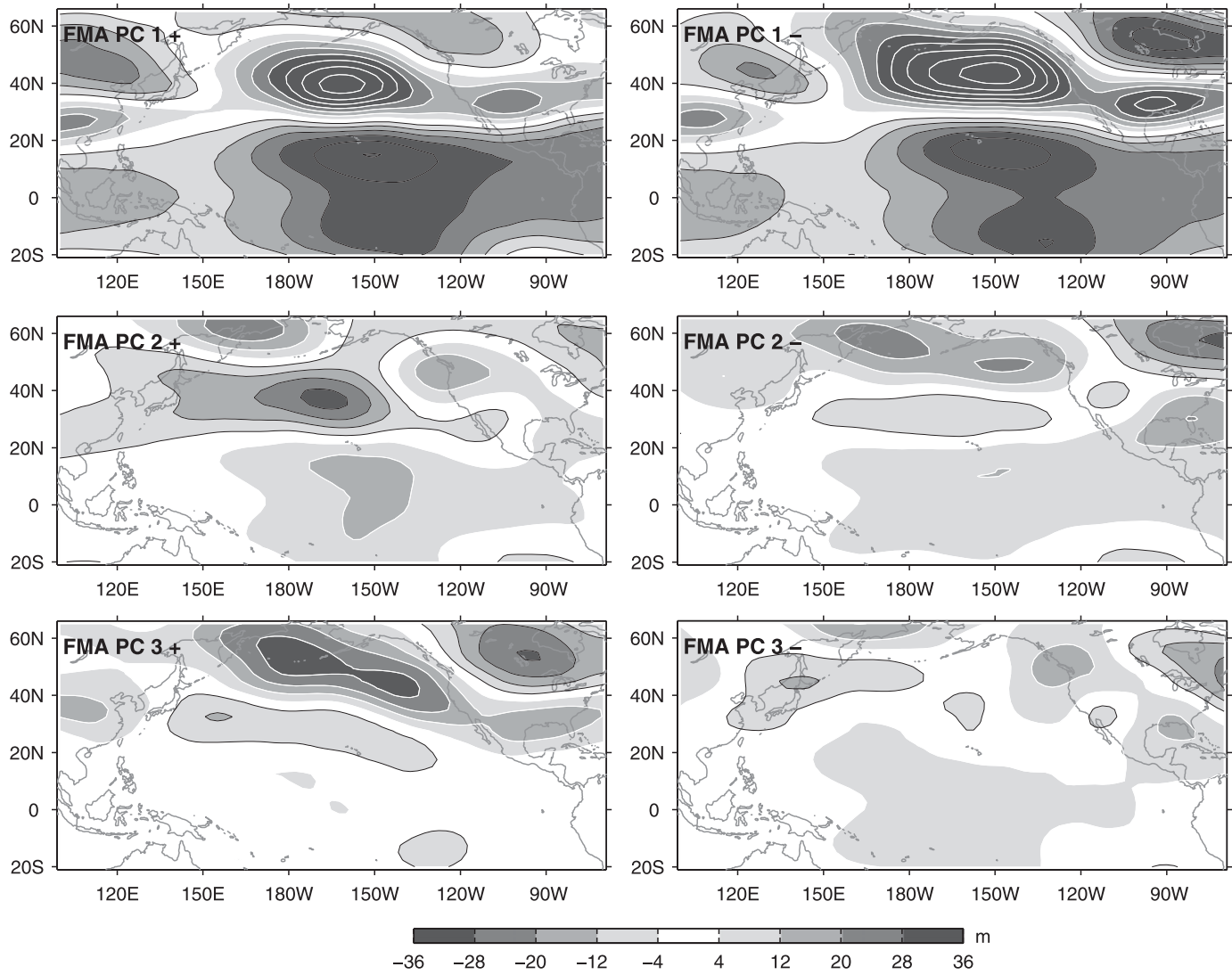

FIG. A2. Regression of the geopotential height anomalies at $250 \mathrm{hPa}$ (in m) onto (left) positive and (right) negative values of (top to bottom) ENSO PC1, PC2, and PC3 in March, after removing a cubic trend. White (gray) contours are for negative (positive) values.

The ENSO signal was removed from the atmospheric fields and the WBC indices by multivariate regression. To take into account the asymmetry of the ENSO teleconnections, the mean of the original time series was subtracted from each time series and the regression done separately for positive and negative values of the PCs. The regression is thus based on six time series, which are only pairwise uncorrelated. To represent the seasonality of the ENSO teleconnections, the regression coefficients are seasonally varying, with the multivariate regression for a particular calendar month also using the preceding and the following month (e.g., the regression for February is calculated from January, February, and March of each year). The analysis was also conducted without taking seasonality into account, with broadly similar results. Omitting the asymmetry in the ENSO removal has stronger effects, but it did not substantially change the results.

The asymmetry in the atmospheric anomalies associated with the ENSO PCs varies with the time of year. A typical example is shown for Z250 in March in Fig. A2. If symmetric, the regression maps for positive and negative values should be identical within sampling error. There is relative symmetry for PC1 but a strong asymmetry for PC2 and PC3, especially near the KOE. The signal, baroclinic in the tropics and equivalent barotropic elsewhere, typically reaches about $50 \mathrm{~m}$ in winter and $20 \mathrm{~m}$ in summer at $250 \mathrm{hPa}$ for PC1 and somewhat less for PC2. It is shown below that the estimated North Pacific response at $250 \mathrm{hPa}$ to typical $\mathrm{WBC}$ changes is $15 \mathrm{~m}$ for the $\mathrm{KE}$ and $35 \mathrm{~m}$ for the OE. Hence, the removed ENSO signal may be larger than the signal of interest, consistent with the larger efficiency of tropical boundary forcing compared to the midlatitude one (e.g., Kushnir et al. 2002). This stresses the importance of removing the ENSO teleconnections as carefully as possible.

The efficiency of the ENSO removal is illustrated for SST, as it shows that the SST residual is negligible in the tropics. The SST anomalies associated with the ENSO events can be described by composites. In the period of interest, the "year 0" El Niño events take place in 1982, 1987, 1997, 2002, 2004, and 2006, and La Niña events in 1988, 1998, 1999, and 2007. The difference between the El Niño composite and La Niña composite (based on the 

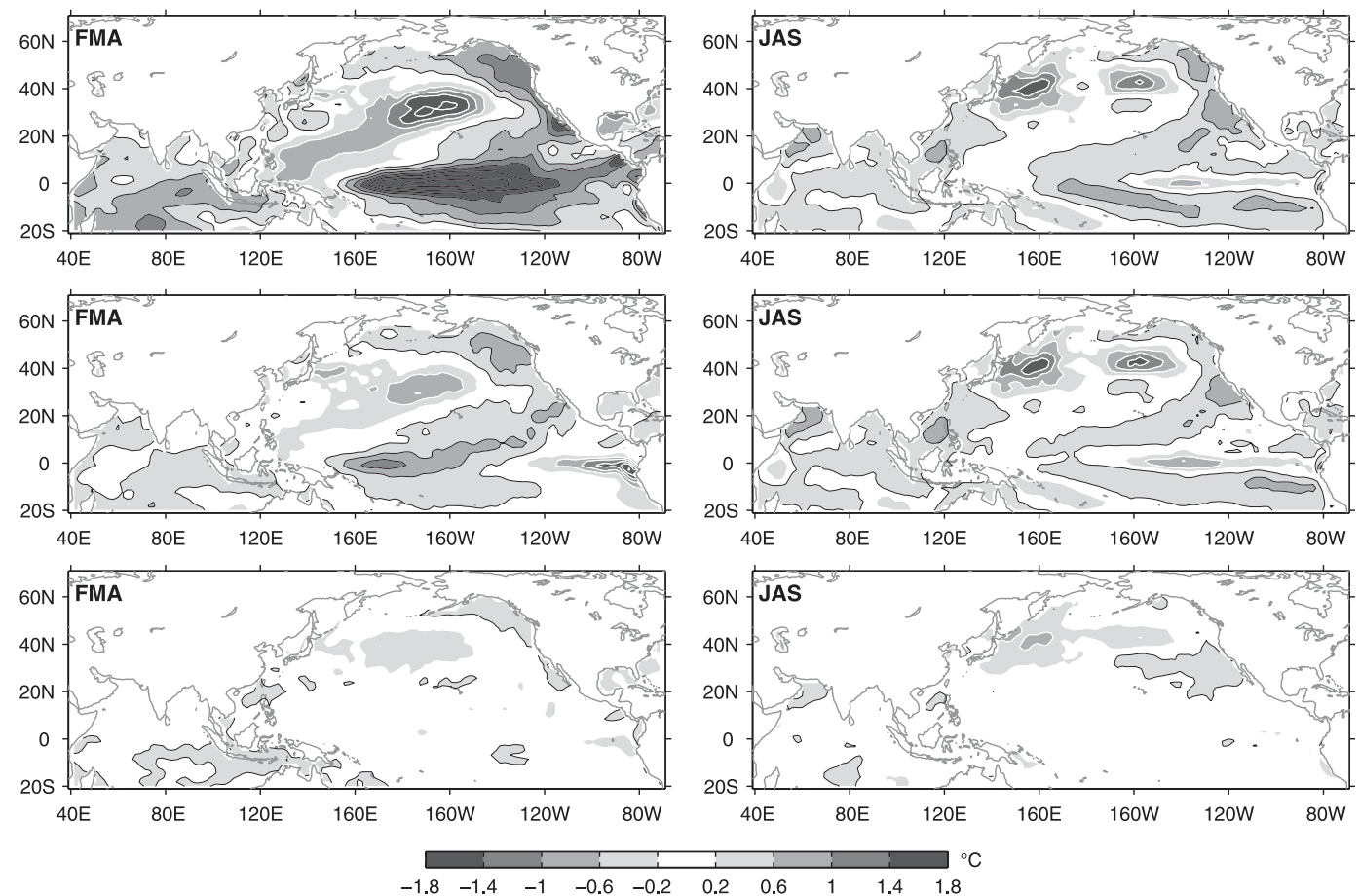

FIG. A3. Difference between (top) El Niño and La Niña composites, (middle left) SST residuals when using ENSO PC1 or (middle right) ENSO PC1 and PC2, and (bottom) when using all three PCs for (left) FMA(1) and (right) JAS(1). White (gray) contours are for negative (positive) values.

NCEP-NCAR reanalysis SST) is shown in Fig. A3 (left) for February-April (FMA) of "year 1," near the peak of the ENSO events. The SST signal linked to ENSO is dominated by the regressions on PC1; however, it is also affected by PC2 and, to a much lesser extent, PC3, as shown by the comparison between the SST residual based on PC1 only (middle left panel) and that based on all three PCs (bottom left panel). ENSO filtering has often been solely based on the Niño-3.4 index (e.g., Liu et al. 2006; Qiu et al. 2007), which roughly corresponds to ENSO PC1. Figure A3 shows that a single index does not suffice to remove the SST signal in the tropics, but that three indices do it reasonably well. This holds for the atmospheric ENSO teleconnections. Using three tropical Pacific PCs in the regressions has reduced the SST residual in the North Pacific, but recall that it is an average of, presumably, independent events due to intrinsic midlatitude atmospheric forcing and WBC changes (which may in part be a lagged response to ENSO forcing). The ENSO removal is also shown for July-September (JAS) of year 1, when ENSO events are largely terminated (Fig. A3, right). The comparison between the residuals using two (middle right) and three (bottom right) PCs shows that the SST signal linked to the third PC has become large at tropical and extratropical latitudes. The largest contribution arises from the La Niña events.
It should be stressed that the ENSO removal, as done in this study, is solely aimed at estimating the atmospheric response to extratropical boundary forcing. It does not separate the response of the WBCs to the extratropical atmospheric variability from that of ENSO teleconnections because the WBCs respond as integrators of the atmospheric forcing, thus depending on its time history. This also holds for SST. Separation could only be attempted by using a specific model of the oceanic response, as in Schneider and Cornuelle (2005).

\section{REFERENCES}

Bretherton, C. S., M. Widmann, V. P. Dymnikov, J. M. Wallace, and I. Bladé, 1999: The effective number of spatial degrees of freedom of a time-varying field. J. Climate, 12, 1990-2009.

Bretherton, F. P., R. E. Davis, and C. B. Fandry, 1976: A technique for objective analysis design of oceanographic experiments applied to mode 73. Deep-Sea Res., 23, 559-582.

Ceballos, L. I., E. Di Lorenzo, C. D. Hoyos, N. Schneider, and B. Taguchi, 2009: North Pacific gyre oscillation synchronizes climate fluctuations in the eastern and western boundary systems. J. Climate, 22, 5163-5174.

Czaja, A., and C. Frankignoul, 1999: Influence of the North Atlantic SST on the atmospheric circulation. Geophys. Res. Lett., 26, 2969-2972.

$\longrightarrow$, and - 2002: Observed impact of Atlantic SST anomalies on the North Atlantic Oscillation. J. Climate, 15, 606-623. 
Deser, C., R. Thomas, and S. Peng, 2007: The transient atmospheric circulation response to North Atlantic SST and sea ice anomalies. J. Climate, 20, 4751-4767.

Feliks, Y., M. Ghil, and E. Simonnet, 2004: Low-frequency variability in the midlatitude atmosphere induced by an oceanic thermal front. J. Atmos. Sci., 61, 961-981.

Ferreira, D., and C. Frankignoul, 2005: The transient atmospheric response to midlatitude SST anomalies. J. Climate, 18, 10491067

, and - 2008: Transient atmospheric response to interactive SST anomalies. J. Climate, 21, 576-583.

Frankignoul, C., and E. Kestenare, 2002: The surface heat flux feedback. Part I: Estimates from observations in the Atlantic and the North Pacific. Climate Dyn., 19, 633-647.

— SST anomalies on the atmospheric circulation. J. Climate, 20, 592-606.

— A. Czaja, and B. L'Heveder, 1998: Air-sea feedback in the North Atlantic and surface boundary conditions for ocean models. J. Climate, 11, 2310-2324.

_ - G. de Coëtlogon, T. M. Joyce, and S. Dong, 2001: Gulf Stream variability and ocean-atmosphere interactions. J. Phys. Oceanogr., 31, 3516-3529.

Hirose, N., K. Nishimura, and M. Yamamoto, 2009: Observational evidence of a warm ocean current preceding a winter teleconnection pattern in the northwestern Pacific. Geophys. Res. Lett., 36, L09705, doi:10.1029/2009GL037448.

Hoerling, M. P., A. Kumar, and M. Zhong, 1997: El Niño, La Niña, and the nonlinearity of their teleconnections. J. Climate, 10, 1769-1786.

Isoguchi, O., H. Kawamura, and T. Kono, 1997: A study of windgriven circulation in the subarctic North Pacific using TOPEX/ POSEIDON altimeter data. J. Geophys. Res., 102, $12457-$ 12468.

Johnson, D. R., and Coauthors, 2006: World Ocean Database 2005 documentation. S. Levitus, ed., NODC Internal Rep. 18, 163 pp. [Available online at ftp://ftp.nodc.noaa.gov/pub/WOD05/DOC/ wod05readme.pdf.]

Joyce, T. M., Y.-O. Kwon, and L. Yu, 2009: On the relationship between synoptic wintertime atmospheric variability and path shifts in the Gulf Stream and the Kuroshio Extension. J. Climate, 22, 3177-3192.

Kao, H.-S., and J.-Y. Yu, 2009: Contrasting eastern-Pacific and central-Pacific types of ENSO. J. Climate, 22, 615-632.

Kelly, K. A., R. J. Small, R. M. Samelson, B. Qiu, T. M. Joyce, Y.-O. Kwon, and M. F. Cronin, 2010: Western boundary currents and frontal air-sea interaction: Gulf Stream and Kuroshio Extension. J. Climate, 23, 5644-5667.

Kistler, R., and Coauthors, 2001: The NCEP-NCAR 50-Year Reanalysis: Monthly means CD-ROM and documentation. Bull. Amer. Meteor. Soc., 82, 247-267.

Kushnir, Y., and N.-C. Lau, 1992: The general circulation model response to a North Pacific SST anomaly: Dependence on time scale and pattern polarity. J. Climate, 5, 271-283.

— W. A. Robinson, I. Bladé, N. M. J. Hall, S. Peng, and R. Sutton, 2002: Atmospheric GCM response to extratropical SST anomalies: Synthesis and evaluation. J. Climate, 15, 22332256.

Kwon, Y.-O., and C. Deser, 2007: North Pacific decadal variability in the Community Climate System Model version 2. J. Climate, 20, 2416-2433.

—, M. A. Alexander, N. A. Bond, C. Frankignoul, H. Nakamura, B. Qiu, and L. A. Thompson, 2010a: Role of the Gulf Stream and Kuroshio-Oyashio systems in large-scale atmosphereocean interaction: A review. J. Climate, 23, 3249-3281.

— C. Deser, and C. Cassou, 2010b: Coupled atmosphere-mixed layer ocean response to ocean heat flux convergence along the Kuroshio Current Extension. Climate Dyn., in press, doi:10.1007/s00382-010-0764-8.

Latif, M., and T. P. Barnett, 1994: Causes of decadal climate variability over the North Pacific and North America. Science, 266, 634-637.

Le Traon, P. Y., 1990: A method for optimal analysis of fields with spatially variable mean. J. Geophys. Res., 95 (C8), $13543-$ 13547.

Linkin, M. E., and S. Nigam, 2008: The North Pacific Oscillationwest Pacific teleconnection pattern: Mature-phase structure and winter impacts. J. Climate, 21, 1979-1997.

Liu, Q., N. Wen, and Z. Liu, 2006: An observational study of the impact of the North Pacific SST on the atmosphere. Geophys. Res. Lett., 33, L18611, doi:10.1029/2006GL026082.

Liu, Z., and M. Alexander, 2007: Atmospheric bridge, oceanic tunnel, and global climatic teleconnections. Rev. Geophys., 45, RG2005, doi:10.1029/2005RG000172.

Mantua, N. J., S. R. Hare, Y. Zhang, J. M. Wallace, and R. Francis, 1997: A Pacific interdecadal climate oscillation with impacts on salmon production. Bull. Amer. Meteor. Soc., 78, 1069-1079.

Minobe, S., A. Kuwano-Yoshida, N. Komori, S. Xie, and R. J. Small, 2008: Influence of the Gulf Stream on the troposphere. Nature, 452, 206-209.

Nakamura, H., and A. S. Kazmin, 2003: Decadal changes in the North Pacific oceanic frontal zones as revealed in ship and satellite observations. J. Geophys. Res., 108, 3078, doi:10.1029/ 1999JC000085.

_, G. Lin, and T. Yamagata, 1997: Decadal climate variability in the North Pacific during the recent decades. Bull. Amer. Meteor. Soc., 78, 2215-2225.

_ , T. Sampe, Y. Tanimoto, and A. Shimpo, 2004: Observed associations among storm tracks, jet streams and midlatitude oceanic fronts. Earth Climate: The Ocean-Atmosphere Interaction, Geophys. Monogr., Vol. 147, Amer. Geophys. Union, 329-346.

Nonaka, M., H. Nakamura, Y. Tanimoto, T. Kagimoto, and H. Sasaki, 2006: Decadal variability in the Kuroshio-Oyashio Extension simulated in an eddy-resolving OGCM. J. Climate, 19, 19701989.

,,,--- , and,- 2008: Interannual-to-decadal variability in the Oyashio Current and its influence on temperature in the subarctic frontal zone: An eddy-resolving OGCM simulation. J. Climate, 21, 6283-6303.

Peng, S., W. A. Robinson, and S. Li, 2002: North Atlantic SST forcing of the NAO and relationships with intrinsic hemispheric variability. Geophys. Res. Lett., 29, 1276, doi:10.1029/ 2001 GL014043.

,$--\frac{1}{-}$, and -2003 : Mechanisms for the NAO responses to the North Atlantic SST tripole. J. Climate, 16, 1987-2004.

Pierce, D. W., T. P. Barnett, N. Schneider, R. Saravanan, D. Dommenget, and M. Latif, 2001: The role of ocean dynamics in producing decadal climate variability in the North Pacific. Climate Dyn., 18, 51-70.

Qiu, B., 2002: Large-scale variability in the midlatitude subtropical and subpolar North Pacific Ocean: Observations and causes. J. Phys. Oceanogr., 32, 353-375.

_ 2003: Kuroshio Extension variability and forcing of the Pacific decadal oscillations: Responses and potential feedback. J. Phys. Oceanogr., 33, 2465-2482. 
- and S. Chen, 2005: Variability of the Kuroshio Extension jet, recirculation gyre, and mesoscale eddies on decadal time scales. J. Phys. Oceanogr., 35, 2090-2103.

$\longrightarrow$, and — 2010: Eddy-mean flow interaction in the decadally modulating Kuroshio Extension system. Deep-Sea Res. II, 57, 1097-1110.

— North Pacific: Observationally constrained idealized model. J. Climate, 20, 3602-3620.

Reynolds, R. W., T. M. Smith, C. Liu, D. B. Chelton, K. S. Casey, and M. G. Schlax, 2007: Daily high-resolution blended analyses for sea surface temperature. J. Climate, 20, $5473-$ 5496.

Rodwell, M. J., and C. K. Folland, 2002: Atlantic air-sea interaction and seasonal predictability. Quart. J. Roy. Meteor. Soc., 128, 1413-1443.

Schneider, N., and B. D. Cornuelle, 2005: The forcing of the Pacific decadal oscillation. J. Climate, 18, 4355-4373.

— A. J. Miller, and D. W. Pierce, 2002: Anatomy of North Pacific decadal variability. J. Climate, 15, 586-605.

Seager, R., Y. Kushnir, N. H. Naik, M. A. Cane, and J. Miller, 2001: Wind-driven shifts in the latitude of the Kuroshio-Oyashio Extension and generation of SST anomalies on decadal timescales. J. Climate, 14, 4249-4265.

Small, R. J., and Coauthors, 2008: Air-sea interaction over ocean fronts and eddies. Dyn. Atmos. Oceans, 45, 274-319.
Straus, D. M., and J. Shukla, 2002: Does ENSO force the PNA? J. Climate, 15, 2340-2358.

Strong, C., G. Magnusdottir, and H. Stern, 2009: Observed feedback between winter sea ice and the North Atlantic Oscillation. J. Climate, 22, 6021-6032.

Taguchi, B., S.-P. Xie, N. Schneider, M. Nonaka, H. Sasaki, and Y. Sasai, 2007: Decadal variability of the Kuroshio Extension: Observations and an eddy-resolving model hindcast. J. Climate, 20, 2357-2377.

- , H. Nakamura, M. Nonaka, and S.-P. Xie, 2009: Influences of the Kuroshio/Oyashio Extensions on air-sea heat exchanges and storm-track activity as revealed in regional atmospheric model simulations for the 2003/04 cold season. J. Climate, 22, 6536-6560.

Trenberth, K. E., and D. P. Stepaniak, 2001: Indices of El Niño evolution. J. Climate, 14, 1697-1701.

Vimont, D. J., J. M. Wallace, and D. S. Battisti, 2003: The seasonal footprinting mechanism in the Pacific: Implications for ENSO. J. Climate, 16, 2668-2675.

Vivier, F., K. A. Kelly, and L. Thompson, 2002: Heat budget in the Kuroshio Extension region: 1993-99. J. Phys. Oceanogr., 32, 3436-3454.

von Storch, H., and F. W. Zwiers, 1999: Statistical Analysis in Climate Research. Cambridge University Press, 342 pp.

Wallace, J. M., and D. S. Gutzler, 1981: Teleconnections in the geopotential height field during the Northern Hemisphere winter. Mon. Wea. Rev., 109, 784-812. 